Insight Stem Cell Research 1 (1): 1-5, 2011

ISSN: 2040-7076

(C) 2011 Insight Knowledge, UK

\title{
The Potential of Stem Cells to Correct the Lost Tissue Mass in Liver and Kidney of Rat after Copper Toxicity
}

\author{
O.A. Abu-Zinadah and H.K. Hussein \\ Department of Biological Sciences, Faculty of Science, King Abdulaziz University, \\ P.O. Box 80203, Jeddah 21589, Saudi Arabia
}

\begin{abstract}
Background: The belief is that the genetic defects are responsible for disease and copper toxicosis is a cause rather than the result of tissue disease but it is not the primary cause. The tissue alterations, vacoulation, degeneration and necrosis, decreased after stopping copper toxicity and the organs excrete the excess copper by certain ways. The aim of this study was to show the potential of interstitial stem cells or their precursors to be involved in the regeneration of the lost tissue mass in liver and kidneys after copper toxicity clearance. Result: The present experiment was designed using the local albino Sprague Dawely rats. The animals were sacrificed during and after toxication period as well as after non-toxication periods. Copper accumulates in animal tissues until reaching the toxic level, at which time the histopathological changes then develops. Conclusion: This clearance enhances the interstitial stem cells or their precursors to incorporate in regeneration of the lost tissue mass. Moreover, to some extents, the bone marrow stem cells may introduce some plasticity to regenerate some of this lost tissue mass. The results support the opinion that the interstitial stem cells or even bone marrow stem cells are incorporated into regeneration of the lost tissues after toxication and clearance.
\end{abstract}

Key words: Regeneration, stem cells, copper, toxicities, tissues, rats

\section{INTRODUCTION}

The relationship between dietary copper exposure and body copper nutritional status is complex because copper homeostasis allows a wide range of copper intake without resulting on adverse effects. Hematopoietic stem cells possess an extraordinary developmental renewing capacity. It has been reported that hemopoietic stem cells generate the brain, liver and skeletal muscles (Ferrai et al., 1998; Gussoni et al., 1999; Theise et al., 2000; Lagasse et al., 2000; De Haan, 2002; Rodrigo et al., 2009). On the other hand, muscle and neural stem cells have been reported to generate blood cells (Jackson and Goodell, 1999; Bjornson et al., 1999). In this respect, the use of bone marrow stem cells transplantation to correct disease in an intoxicated mouse (a murine model for Wilson's disease) was evaluated. The transplantation of bone marrow cells partially corrects the metabolic phenotype (Allen et al., 2004; Rodrigo et al., 2009; Christopher, 2010). As we know copper storage disease is known as Wilson's disease in which copper concentration is increased up to 50 times than the normal value (Crawford et al., 1985). Copper accumulates in the liver until reaching toxic levels, at which time pathological changes then develop. The belief is that a genetic defect is responsible for the disease (Crawford et al., 1985). It is suggested that copper toxicosis is a cause rather than a result of liver disease, but not the primary cause (Franklin and Saunders, 1988). An autosomal recessive copper toxicosis gene has been linked to the copper metal metabolism disorder (Brewer et al., 1992).

Bhunya and Jena (1996) studied the clastogenic potential of copper sulphate in chicks. They found an increase in micronucleolus counts in both bone marrow and peripheral blood erythrocytes in time- and doseresponse. This observation reveals the genotoxic potential of copper sulphate in chick in vivo. Similar observation was also recorded by Richards (1999) who revealed some of the distinct changes occurring in the metabolism of zinc, copper, iron in both maternal and fetal tissues fluids during gestation in the pig. Misezta (1990) studied the effects of copper as copper sulphate in the bone marrow cells of rats' in vitro cultures, loosely arranged macrophages, fibroblasts and adipocytes which appeared as early as the control tissue culture. All these observations reflect the different copper mode of actions which includes its accumulation in the cells in greater level than the cellular needs; of these effects is the remodulation of stem cells due to the geno- or cytotoxicity of copper. This suggestion is supported by

Corresponding Author: O.A. Abu-Zinadah, Department of Biological Sciences, Faculty of Science, King Abdulaziz University, P.O. Box 80203 , Jeddah 21589, Saudi Arabia 
Rodriguez et al. (2002) who speculated that copper plays a functional role which stimulates the mesenchymal stem cells differentiation.

Tissue regeneration entails complex interaction between multiple signals and material platforms. Orchestrating of these signals may greatly enhance the regeneration of lost tissue mass. Vascular endothelial growth factors and lost cells precursor capable of responding of these cues and forming the lost tissues. Huang et al. (2005) demonstrated that the bone formation is a coordinated process involving various biological factors. Also, Goldschmidt et al. (2003) found that bone marrow stem cells transplant will lead to maximum tumour reduction and development by modulation to form bone marrow cells. The aim of this study was to show the potential of interstitial stem cells or their precursors to be involved in the regeneration of the lost tissue mass in liver and kidneys after copper toxicity clearance.

\section{MATERIAL AND METHODS}

Eighteen immature local albinos Sprague Dawely rats weighing about $65 \pm 3.5 \mathrm{~g}$ (Vide No. 288, 2010) were obtained from the animal house, King Fahd for medical researches, King Abdulaziz University, Jeddah. The animals were housed in stainless steel cages under room temperature and air conditioning. They were fed commercial diet, vegetables, crushed wheat and corn. They were left for a week to be acclimatized. Then, they were divided into a control group ( 6 animals) and a treated group (12 animals). A dose of $4 \mathrm{mg} \mathrm{CuSO} \mathrm{kg}^{-1}$ b. wt. was force-fed daily by stomach tube to the rats of the second group for three weeks. After each week one rat of the control group and two rats of the treated group were sacrificed. Liver and kidneys were removed, fixed in 10\% neutral formalin, embedded in paraffin wax, sectioned and stained with hematoxylin and eosin. Then, the rest of the experimental animals ( 3 control and 6 treated) were left without copper treatment for other three weeks and after each week one control animal and two animals from the previously treated groups were sacrificed. Also, liver and kidneys were dissected out and treated as mentioned before.

\section{RESULTS}

Macroscopic observation of animals and organs: Liver and kidneys did not show any defects after the first week of copper toxication; no decolourization or hemorrhage were observed except the vomiting of some animals after treatment. At the end of the third week decolouriztion of the all organs was observed. After stopping the copper doses for three weeks all organs restored their normal colours and shapes.
Microscopic examination: Liver sections displayed vacuolations around the central vein. This vacoulation was followed by degeneration of cell masses and finally some necrotic cells were observed (Fig. 1A, B). Kidney's tissues showed signs of degeneration during copper toxicosis. Some uriniferous and collecting tubules were vacuolated and degenerated. The glomeruli were also shrunken and the Bowman's capsules showed some dilatation; these changes were increased by time (Fig. 2A, B).
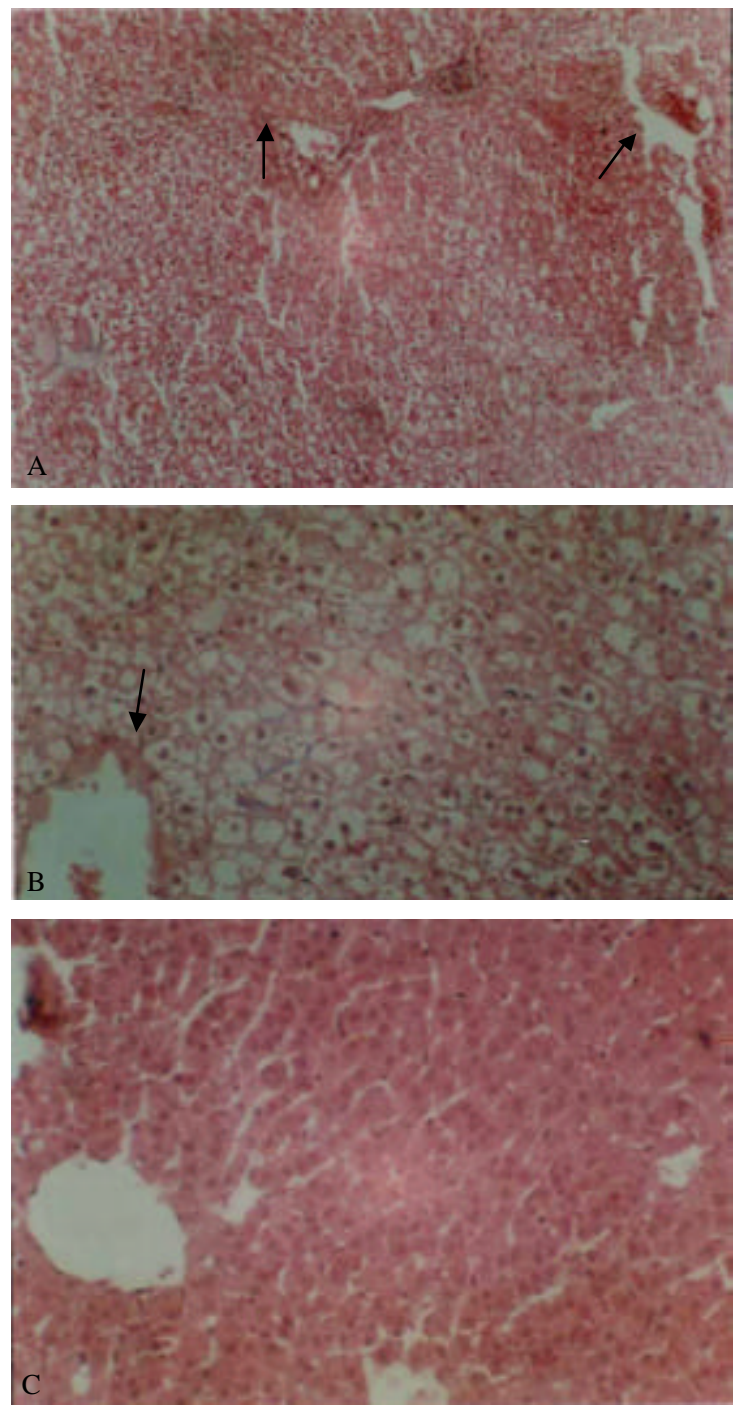

Fig. 1: (A) Liver sections showing vacuolar degeneration around the central vein (arrow); (B) some necrotic cells (head arrow) after the third week of toxication and (C) A liver section shows normal structure after the third week of clearance (H andE) X300 

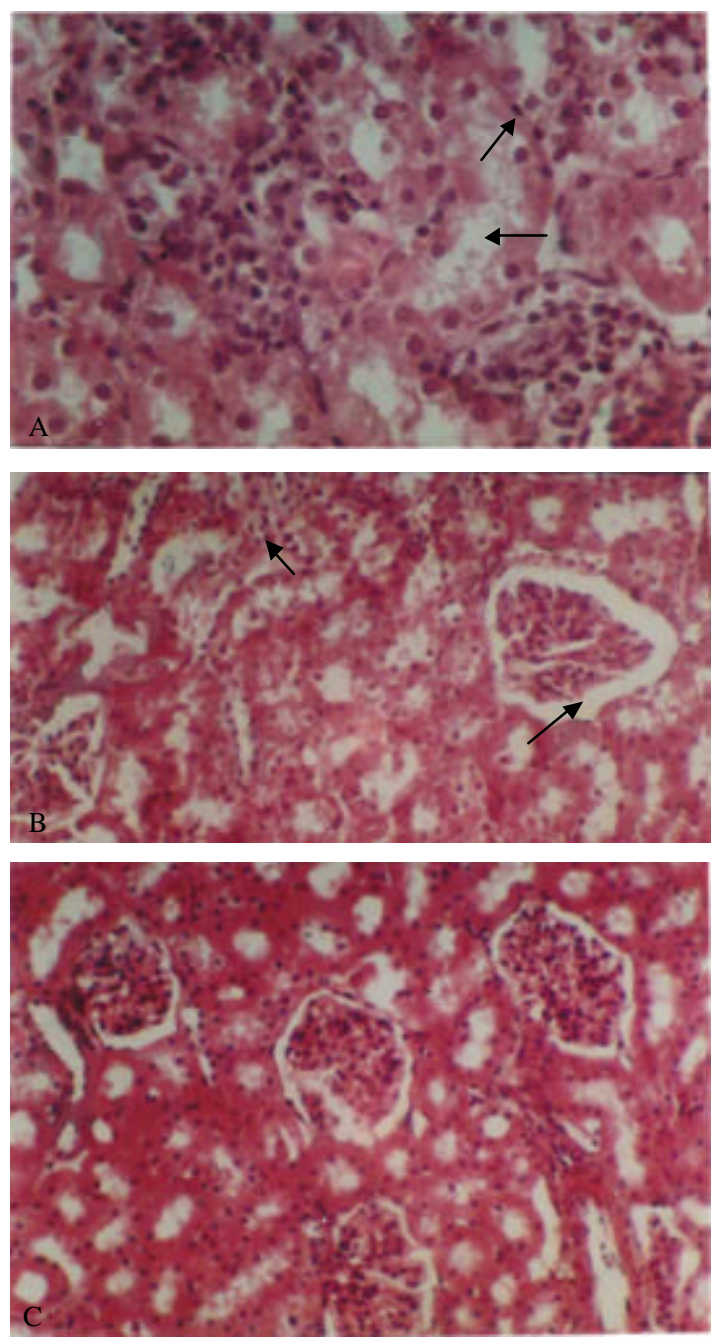

Fig. 2: (A) A kidney section with severe vacuolation of the uriniferous tubules (arrow) and necrotic cells (head arrow); (B) A kidney section shows certain dilatation (arrow) and degeneration of Bowman's capsule (head arrow) and (C) A kidney section shows normal appearance ( $\mathrm{H}$ and $\mathrm{E}$ ), X300

After stopping copper toxicities for one week these alterations were slightly decreased in both liver and kidneys in all animals left for three weeks without treatment. Liver and kidneys almost showed the normal structure and almost all the pathological alterations disappeared (Fig. 1C, 2C).

\section{DISCUSSION}

Diminishing of some degenerative alterations after stopping copper toxicities observed in this study may be due to the clearance of copper toxicities; also regeneration of lost cell masses may be due incorporation of some stem cells to regenerate such lost cell masses. However, the modulation done by copper toxicities to certain cells may enhance them to incorporate or to share partly in regeneration of the lost tissues. The potential of bone marrow stem cells to correct liver dysfunction in the mouse model of Wilson's disease was studied by Allen et al. (2004) who found a direct evidence of functionality and disease correction following liver repopulation. This repopulation was succeeded after bone marrow transplantation which partially corrects the metabolic phenotype in mouse which comes in agreement with our results. Histological examination of liver of cats showed chronic hepatitis and cirrhosis associated with massive accumulation of copper in hepatocytes and macrophages particularly in fibrotic areas between the regenerative nodules. These criteria together with the pattern of hepatic copper storage and the associated inflammation and fibrosis, strongly suggest a primary copper storage disorder (Meertens et al., 2005).

In fact, in normal digestion, food is moved through the digestive tract by rhythmic contractions called peristalsis. When animal suffers from a digestive motility disorder, these contractions are abnormal. This disorder can be due to one of two causes: a problem within the muscle itself followed by disturbance in the intracellular lining or a problem with the nerves or hormones that control the muscle's contractions (Bowen, 2002) which support our observations and may demonstrate the reason of vomiting of some experimental animals after treatment.

On the other hand, the partial recovery of liver and kidney degenerated cells may be due to the fact that such organs get rid of excess copper accumulated during toxication by certain ways. Data which obtained here was supported by Thornburg et al. (1986) who concluded that copper concentration in the liver actually decreases after necrosis and thus repair occurs. The cells that die during necrosis are the same ones that are first to accumulate copper. As the cells die, copper is released into the blood and excreted in urine as the hepatocytes are regenerated and scar tissue is formed.

The renewal of hepatocytes may be due to corporation of certain growth factors or the interstitial stem cells with some plasticity generate the hepatocytes (Ferrai et al., 1998; Gussoni et al., 1999; Theise et al., 2000; Lagasse et al., 2000; Gillson, 2006).

It was observed that the cytotoxicity of certain compounds, copper compound included, to the renal epithelial cells is due to the generation of reactive oxygen precise and peroxidation or may depend upon depletion 
of cellular glutathione GSH (Nakanishi et al., 2005). So, by excretion of excess copper, this is followed by depletion of reactive oxygen precise and peroxidation as well as increase of glutathione (GSH) levels may play a role in regeneration of the altered areas in liver and kidneys (Nakanishi et al., 2005). Tyrosine kinase receptors play an important role in proliferation and differentiation of cells (Visser et al., 1996) including hemopoietic growth factor receptors (Rosnet et al., 1993).

Moreover, Galhardi et al. (2004) investigated the effect of copper intake on lipid profile oxidative stress and tissues damage. It was concluded that copper renal toxicity was associated with oxidative stress and reduction of at least one of the antioxidant enzymes. Our results were come in agreement with the opinion stated that after clearing of copper toxicosis bone marrow cells may contribute to regeneration of damaged glomerular endothelial cells and show some plasticity and can differentiate into a wide range of specialized cells and promoting angiogenesis in regions of progressive glomerular lesions (Ikarashi et al., 2006).

\section{REFERENCES}

Allen, K.J., D.M. Cheah, X.L. Lee, N.E. Pettigrew-Buck and J. Vadolas et al., 2004. The potential of bone marrow stem cells to correct liver dysfunction in a mouse model of Wilson's disease. Cell Transplant., 13: $765-773$.

Bhunya, S.P. and G.B. Jena, 1996. Clastogenic effects of copper sulphate in chick in vivo test system. Mutat. Res., 367: 57-63.

Bjornson, C., R.L. Rietzle, B.A. Roynoids, M.C. Magli and A.L. Vescovi, 1999. Turning brain into blood: Hematopoietic fate adapted by adult neural stem cells in vivo. Science, 283: 534-537.

Bowen, R., 2002. Gastrointestinal Motility and Smooth Muscles. Health on the Net Foundation, Geneva.

Brewer, G.J., W. Schall, R. Dick, G.V. Yuzbasiayan, M. Thomas and G. Padgett, 1992. Ues of 64 copper measurements to diagnose canine copper toxicosis. J. Vet. Int. Med., 6: 41-43.

Christopher, S.W., 2010. Effects of tempol and redoxcycling nitroxides in models of oxidative stress. Pharmacol. Therapeutics, 126: 119-145.

Crawford, M.A., W.D. Schall and J.B. Tasker, 1985. Chronic active hepatitis in 26 doberman pinschers. J. Am. Vet. Assoc., 187: 1343-1349.

De Haan, G., 2002. Hematopoietic stem cells: Selfrenewing or aging. Cells Tissues Organs., 171: 27-37.

Ferrai, G., G. Cusell-de Angelis, M. Coltta, E. Paolucci, A. Stronaiuolo, G. Cossu and F. Mavillio, 1998. Muscle regeneration by bone marrow derived myogenic progenitors. Science, 279: 1528-1530.
Franklin, J.E. and G.K. Saunders, 1988. Chronic active hepatitis in doberman pinschers. Compendium Sm. An., 10: 1247-1254.

Galhardi, C.M., Y.S. Diniz, L.A. Faine, H.G. Rorigue, R.C. Burneiko, B.O. Ribas and E.L. Vovelli, 2004. Toxicity of copper intake; Lipid profile, Oxidative stress and susceptibility to renal dysfunction. Food Chem. Toxicol., 42: 2053-2060.

Gillson, S., 2006. Gastrointestinal Motility Disorders. Health on the Net Foundation, Geneva.

Goldschmidt, H., G. Egerer, S. Fruehauf and A.D. Ho, 2003. Stem cells in hematology and oncology. Med. Klin., 2: 11-14.

Gussoni, E., Y. Soneoka, C.D. Strickland, E.A. Buzney and M.K. Khan et al., 1999. Dystrophin expression in the $\mathrm{mdx}$ mouse restored by stem cell transplantation. Nature, 243: 390-394.

Huang, Y.C., D. Kaigler, K.G. Rice, P.H. Krebsbach and D.J. Mooney, 2005. Combined antigenic and osteogenic factor delivary enhances bone marrow stromal cell-deriven bone marrow regeneration. J. Bone Miner. Res., 20: 848-857.

Ikarashi, K., B. Li, M. Suwa, K. Kawamura and T. Morioka et al., 2006. Bone marrow cells contribute to regeneration of damaged glomerular endothelial cells. Kidney Int., 67: 1925-1933.

Jackson, K.A. and M.A. Goodell, 1999. Hemopoietic potential of stem cells isolated from murine skeletal muscle. Proc. Nat. Acad. Sci., 96: 14482-14486.

Lagasse, E., H. Connors, M. Al-Dhalimy, M. Reitsma and M. Dohse et al., 2000. Purified hematopoietic stem cells can differentiate into hepatocytes in vivo. Nat. Med., 6: 1229-1234.

Meertens, N.M., C.A. Bokhove and T.S. van den Ingh, 2005. Copper associated chronic hepatitis and cirrhosis in a European Shorthair cat. Vet. Pathol., 42: $97-100$.

Misezta, H., 1990. In vito effect of copper on the stromal cells of bone marrow in rats. Toxicol. Ind. Health, 6: 33-39.

Nakanishi, T., E.R. Akabana, M. Nanami, Y. Kiyobayashi and R. Moriguchi et al., 2005. Comparison of cytotoxicity of cysteine and homocysteine for renal epithelial cells. Nephron Exp. Nephrol., 100: 11-20.

Richards, M.P., 1999. Zinc, copper and iron metabolism during porcine fetal development. Biol. Traco Elem. Res., 69: 27-44.

Rodrigo, F., S. Roberto, M. Elsa and I. Mihalis, 2009. Environmental toxicity, oxidative stress and apoptosis: Ménage à trois. Mutat. Res./Genet. Toxicol. Environ. Mutagenesis, 674: 3-22. 
Rodriguez, J.P., S. Rios and M. Gonzalez, 2002. Modulation of the proliferation and differentiation of human mesenchymal stem cells by copper. J. Cell Biochem., 85: 92-100.

Rosnet, O., D. Stephenson, M.G. Mattel, S. Marchetto, M. Shibuya, V.M. Chapman. and D. Birnbaum, 1993. Close physical linkage of the FLTI and FLT3 genes on chromosome 13 in man and chromosome 5 in mouse. Oncology, 8: 173-197.

Theise, N.D., M. Nimmakayalu, R. Gardner, P.B. Illei and G. Morgan et al., 2000. Liver from bone marrow in humans. Hepatology, 32: 11-16.
Thomburg, L.P., G. Rottinghaus and H. Gage, 1986. Chronic liver disease associated high hepatic copper concentration in a dog. J. Am. Vet. Assoc., 188: 1190-1191.

Visser, M., D. Renate, R. Willemze and E.J. Landegent, 1996. Haemopoietic growth factor tyrosine kinase receptor expression profiles in normal haemopoiesis. Br. J. Hematol., 94: 236-241. 